\title{
Ambulatory 24 hour intraesophageal pH-monitoring in the diagnosis of gastroesophageal reflux disease
}

\author{
F JOHNSSON, B JOELSSON AND P-E ISBERG \\ From the Departments of Surgery and Statistics, Lund University, Lund, Sweden
}

SUMmARY The results of ambulatory 24 hour oesophageal $\mathrm{pH}$ monitoring in 20 patients with established gastro-oesophageal reflux disease were compared with those of 20 healthy individuals with normal endoscopy. Cut off limits of $\mathrm{pH} \mathrm{3,4}$, and 5 were superior to $\mathrm{pH} 2$ with respect to the discrimination of patients from normal subjects, and for the detection of pathological reflux. Using $\mathrm{pH} 4$ as a cut off limit, the ambulant and recumbent periods of $\mathrm{pH}$ monitoring were more discriminatory than the postprandial period. Furthermore, it was possible to get complete separation between patients and normal subjects using several combinations of two reflux variables. Another group of 30 patients and 30 controls were investigated. Using percentage time at $\mathrm{pH}<4$ as a single determinant of gastro-oesophageal reflux, the sensitivity and specificity were $87 \%$ and $97 \%$, respectively, with $3.4 \%$ as upper limit for normality. Twenty four hour oesophageal $\mathrm{pH}$ monitoring in an ambulatory outpatient environment afforded clinically useful diagnostic accuracy in separating patients with gastro-oesophageal reflux disease from asymptomatic controls.

During recent decades intraluminal oesophageal $\mathrm{pH}$ measuring has become an increasingly important test of the function of the cardia and the distal oesophagus. The development from short term reflux tests (Tuttles test, SART) ' 2 to longterm $\mathrm{pH}$ studies has meant an extension from a spot test of the competency of the cardia to the ability to classify temporal patterns of reflux. Furthermore, it has provided the possibility of correlating reflux to symptoms and to evaluate the ability of the distal oesophagus to clear refluxed material. ${ }^{24}$ The introduction of equipment for ambulatory outpatient $\mathrm{pH}$ monitoring has been another step in this development. Outpatient monitoring provides more physiologic monitoring conditions, reduced costs, and simpler procedures for the patients. ${ }^{(-9)}$

The purpose of this study was to define the best indicators of gastro-oesophageal reflux disease from 24 hour $\mathrm{pH}$ monitoring. This included the determination of which cut off $\mathrm{pH}$ level best defined a reflux

Address for correspondence: Folke Johnsson. Department of Surgery. Lund University, S-221 85 Lund. Sweden.

Received for publication 29 January 1987 episode and which variable or combinations of variables reflect the amount of reflux. Furthermore, we wanted to investigate whether $\mathrm{pH}$-monitoring over different time periods (ambulant, recumbent and postprandial) would help to distinguish between physiological and pathological reflux.

\section{Methods}

SUBJECTS

Oesophago-gastro-duodenoscopy, oesophageal manometry and ambulatory 24 hour oesophageal $\mathrm{pH}$ monitoring were carried out in 20 patients $(15$ men) with a median age of 51 years (range 28-74) referred to the oesophageal laboratory of our institution. They all complained of heartburn and acid regurgitation and had endoscopic evidence of grade II or III oesophagitis. None had previous oesophageal or gastric surgery and there was no gastric pathology at endoscopy. Oesophageal manometry excluded the diagnoses of achalasia, diffuse oesophageal spasm, or scleroderma.

The same three investigations were done in 20 normal volunteers, (10 men) aged 32-76 years 
(median 40.5) with no previous or present symptoms of gastrointestinal disease and no medication of any kind. All had normal endoscopy and were recruited from the hospital staff and their relatives and were paid a small sum for their participation.

The data from the $\mathrm{pH}$ monitorings in the two groups were compared in order to elucidate the best determinants of gastro-oesophageal reflux disease.

To define the sensitivity and specificity of these determinants another 30 patients (13 men), median age 52 years (range 21-78), and another 30 volunteers (eight men), median age 34 years (range $30-57$ ) were investigated. Inclusion criteria and investigations were identical to those previously described. An additional five volunteers were investigated and excluded because of pathological findings at endoscopy, two had grade 2 oesophagitis and three had hiatal hernia at endoscopy.

The 95th percentile of the reflux variables from all the 50 normal subjects in this study, age $30-76$ years (median 38), was calculated. This may be used as an upper reference limit. The commonly used mean \pm 2 SD was not applicable because the data are skewed and far from normally distributed.

There was a significant difference in age between the 50 patients and the 50 normal subjects, median 51 and 38 years, respectively (Mann-Whitney U-test, $p<0 \cdot 01)$. No significant difference in sex distribution between the groups was found (Fisher's exact test).

\section{EN DOSCOPY}

Oesophagitis was defined as follows: grade I erythema of the oesophageal mucosa; grade II erosions or ulcerations; grade III - granulated epithelium with a cobble stone appearance: grade IV - stricture formation. A hiatal hernia was diagnosed if the distance between the diaphragmatic crura and the squamocolumnar epithelial junction exceeded $2 \mathrm{~cm}$ at endoscopy."'

\section{OESOPHAGEAL MANOMETRY}

This was done using a three lumen water perfused catheter connected to an Arndorfer hydrocapillary pump, the distal side openings on the catheter differentiating $120^{\circ}$ in radial orientation and placed $5 \mathrm{~cm}$ apart. The stationary pull-through technique was used.

\section{HOUR OESOPHAGEAI. $\mathrm{pH}$ MONITORING}

This was done using a Synectics portable $\mathrm{pH}$ measuring unit consisting of an antimony $\mathrm{pH}$ electrode, a silver-silverchloride cutaneous reference electrode and a portable solid state memory unit. The monocrystalline antimony $\mathrm{pH}$ electrode has a diameter of $2.1 \mathrm{~mm}$ and a response time of $90 \%$ within 30 seconds." After calibration in buffer solution at $\mathrm{pH} 1$ and 7 the electrode was introduced through the nose and its tip was placed $5 \mathrm{~cm}$ above the oral margin of the distal oesophageal sphincter previously located by manometry. The reference electrode was placed on the chest and the digital memory box was worn on a waistbelt. The patients were instructed to spend 12 hours ambulant and 12 hours recumbent. Furthermore, they were encouraged to be as normally active as possible during the upright period, at home or at work, and told to eat normal meals with the exception of acid food and beverages. Smoking was allowed but not alcohol consumption. Postprandial time was defined as one hour after each meal. Medication for gastro-oesophageal reflux was withdrawn one week before the investigation.

The $\mathrm{pH}$ monitorings were analysed by a computer program (Esophogram, Synectics). The variables shown in Table 1 were calculated at the $\mathrm{pH}$ cut off

Table 1 Variables analysed from the data obtained by 24 hour $\mathrm{pH}$ monitoring at four different $\mathrm{pH}$ levels $(2,3,4$, and 5)

Number of reflux episodes

Mean number of reflux episodes per hour

Number of episodes longer than five minutes

Length of the longest episode

Mean length of reflux episodes (oesophageal clearance)

Percentage time spent with a pH below the chosen cut off limit

Frequency duration index $(F D I)=$ mean number of reflux episodes per hour $\times$ mean cumulative duration of reflux episodes per hour ${ }^{2}$

All variables were analysed for the periods spent ambulant and recumbent as well as for the postprandial time and the total 24 hours.

limits 2,3,4, and 5. A reflux episode was said to occur when $\mathrm{pH}$ fell below a given cut off limit and to end when $\mathrm{pH}$ returned above the limit. $\mathrm{pH}$ had to rise one unit above the cut off limit, however, before a new episode was considered to occur. A correction was made for the error of not discovering new reflux episodes during the time spent with $\mathrm{pH}$ below the cut off limit. ${ }^{+}$

By comparing the data from the patients and the normal subjects the ability of the variables, alone and in combination, to separate the two study groups was tested in three different respects: (1) Different $\mathrm{pH}$ levels as cut off limits for registration of acid reflux. (2) At a given cut off limit, the different time periods of the $\mathrm{pH}$ monitoring (ambulant, recumbent, and postprandial). (3) At a given cut off limit, combination of variables.

STATISTICAL ANALYSIS

The data were analysed using a logistic regression model. ${ }^{13}$

The study was approved by the ethical research committee of the Lund University, 24 March, 1984. 


\section{Results}

pH LIMIT FOR REFIUX

Complete discrimination between the 20 patients and the 20 normal subjects could be obtained at all the tested $\mathrm{pH}$ cut off limits $(2,3,4$, and 5) using the data obtained from 24 hour $\mathrm{pH}$ monitoring. It was, however, more difficult at $\mathrm{pH} 2$ where a combination of four variables was needed to get complete discrimination. At $\mathrm{pH} 3,4$, and 5 a combination of only two variables was needed (Table 2 ).

Table 2 Combinations of variables that provided complete separation at the different $\mathrm{pH}$ cut off limits

\begin{tabular}{llll}
\hline$p H 2$ & $p H 3$ & $p H 4$ & $p H 5$ \\
\hline Tot $\%<2$ & Tot $\%<3$ & Tot $\%<4$ & Tot $\%<5$ \\
Rec $\%<2$ & Reclongest & Reclongest & Reclongest \\
Rec FDI & episode & episode & episode \\
$\begin{array}{c}\text { Postprandial } \\
\text { clearance }\end{array}$ & & & \\
\hline
\end{tabular}

Tot $\%<=$ percentage time with $\mathrm{pH}$ below the cut of limit, total time; $R$ ec $\%<=$ percentage time with pH below the cut off limit, recumbent $; \mathrm{FDI}=$ frequency duration index .

These results indicate that $\mathrm{pH} 4$ is a good cut off limit for detection of acid reflux. It is equally potent as $\mathrm{pH} 3$ and 5 and is in our opinion preferable as it is the most commonly used. Thus $\mathrm{pH} 4$ was selected for determination of variables and reference limits.

DIFFERENT PERIODS OF THE PH MONITORING ( $\mathrm{pH} 4$ AS CUT OFF LIMIT FOR REFLUX)

By using combinations of the reflux variables obtained during either the ambulant or the recumbent periods, perfect separation between the groups was obtained. In the ambulant period a combination of two variables and, in the recumbent, three variables were needed for complete discrimination.

In contrast discrimination between patients and normal subjects was not possible using any combination of the variables from the postprandial period.

\section{REFLUX VARIABLES ( $\mathrm{pH} 4$ AS CUT OFF LIMIT FOR} REFLUX )

No single variable from Table 1 was a perfect determinant of disease. The best variables were: percentage time with $\mathrm{pH}$ below 4 for the total monitoring and frequency duration indices (FDI) for the ambulant period and the total monitoring. The differences between these variables were not statistically significant.

Many combinations of variables discriminated perfectly between patients and normal subjects. From the best single variables the percentage time spent with a pH below 4 was selected as it is easier to calculate and comprehend than FDI. A combination of the length of the longest episode recumbent and the percentage time with $\mathrm{pH}$ below 4 then discriminated perfectly.

\section{SENSITIVITY AND SPECIFICITY ( $\mathrm{pH} 4$ AS CUT OFF} LIMIT FOR REFLUX)

From another 30 normal subjects and another 30 patients the percentage time with $\mathrm{pH}$ below 4 and the length of the longest reflux episode recumbent was obtained. These two variables in combination misclassified four of the patients as normal, resulting in a sensitivity of $87 \%$. Only one normal was misclassified. The specificity, thus, was $97 \%$.

The use of combinations of variables as a screening method in daily routine, however, is difficult as it necessitates a mathematical formula or a graphic presentation. We therefore investigated the sensitivity and specificity of percentage time $\mathrm{pH}$ below 4 as a single variable. The value of this variable that minimised the number of misclassifications in the first group of 20 normal subjects and 20 patients was $3.4 \%$ which was used as upper limit for normality. This value had the same sensitivity and specificity as the combination of percentage time and the length of the longest recumbent episode when tested on the second population of 30 normal subjects and 30 patients.

NORMAL POPULATION

Table 3 shows the results of ambulatory 24 hour $\mathrm{pH}$ monitoring in all 50 healthy volunteers with normal endoscopy. Furthermore, the 95th percentile for all variables studied are shown in Table 4.

\section{Discussion}

Pathological gastro-oesophageal reflux is a common disorder. The key to successful treatment is a reliable diagnosis. Longterm $\mathrm{pH}$ monitoring has been shown to be the most accurate test of gastro-oesophageal reflux disease ${ }^{1+17}$ and ambulatory systems have proved to be safe and reliable according to several authors using different techniques. ${ }^{(n-4)}$ is

A drop in oesophageal $\mathrm{pH}$ is used as a sign of acid gastro-oesophageal reflux. In the present study we have compared four $\mathrm{pH}$ cut off limits for reflux, as different cut off limits are recommended in the literature. Lichter proposed $\mathrm{pH} 2 \cdot 3$ as a limit." This is based on a study by Goldberg et al who found that peptic oesophagitis in pigs occurred between $\mathrm{pH}$ 1.3-2.3. ." DeMeester and Johnson"1 $^{21}$ used $\mathrm{pH} 4$ as a limit, because this was considered the subjective limit for pyrosis." Furthermore the pepsin activity is low $(20 \%)$ at $\mathrm{pH} 4$ and none at $\mathrm{pH} 5 .{ }^{23}$ The present clinical study shows that $\mathrm{pH} 2$ is a less suitable cut off 
Table 3 Results of 24 hour pH monitoring in 50 asymptomatic volunteers with normal endoscopy

\begin{tabular}{|c|c|c|c|c|c|}
\hline Subject & Age & Sex & $T o t \%<4$ & $A m b \%<4$ & $\operatorname{Rec} \%<t$ \\
\hline 1 & 33 & $\mathrm{M}$ & $3 \cdot 4$ & $6 \cdot 3$ & 0.8 \\
\hline 2 & 32 & $F$ & $1 \cdot 1$ & $1 \cdot 1$ & $1 \cdot 1$ \\
\hline 3 & 35 & $F$ & 2.9 & $2 \cdot 4$ & $3 \cdot 3$ \\
\hline 4 & 77 & M & $1 \cdot 4$ & 0.3 & $2 \cdot()$ \\
\hline 5 & 68 & $F$ & 0.1 & 0.2 & 0 \\
\hline 6 & 52 & $\mathrm{~F}$ & $1 \cdot 1$ & 0.8 & 1.5 \\
\hline 7 & 39 & $F$ & 0.6 & $1 \cdot 1$ & () \\
\hline 8 & 32 & M & $1 \cdot 4$ & $2 \cdot 9$ & 0 \\
\hline 9 & 40 & $F$ & $1 \cdot 1$ & 0.8 & $1 \cdot 3$ \\
\hline 10 & 31 & $\mathrm{~F}$ & 0.9 & $1 \cdot 8$ & 0.3 \\
\hline 11 & 40 & $F$ & 0.4 & 0.8 & 0 \\
\hline 12 & 40 & $\mathrm{M}$ & $1 \cdot 1$ & 1.9 & (1). 4 \\
\hline 13 & 39 & $\mathrm{~F}$ & $2 \cdot 1$ & 1.5 & $3 \cdot 1$ \\
\hline 14 & 32 & $\mathrm{~F}$ & $2 \cdot 2$ & $4 \cdot 7$ & 0.1 \\
\hline 15 & 41 & $\mathrm{~F}$ & 0.6 & $1 \cdot 0$ & 0.2 \\
\hline 16 & 31 & $\mathrm{~F}$ & $2 \cdot 7$ & $4 \cdot 2$ & $1 \cdot 3$ \\
\hline 17 & 68 & $\mathrm{M}$ & $2 \cdot 3$ & $4 \cdot 7$ & () \\
\hline 18 & 37 & M & $2 \cdot 6$ & $4 \cdot 3$ & $1 \cdot 2$ \\
\hline 19 & 30) & $\mathrm{M}$ & 2.5 & $2 \cdot 4$ & $2 \cdot 6$ \\
\hline 20 & 50 & $\mathrm{~F}$ & 0.4 & 0.8 & 0 \\
\hline 21 & 42 & M & $1 \cdot 2$ & $2 \cdot 4$ & $(0.1$ \\
\hline 22 & 32 & $\mathrm{~F}$ & $1 \cdot 3$ & $2 \cdot 2$ & 0.4 \\
\hline 23 & 35 & $\mathbf{M}$ & 1.8 & 3.9 & 0 \\
\hline 24 & 34 & $\mathrm{~F}$ & $1 \cdot 7$ & $2 \cdot 4$ & $1 \cdot 1$ \\
\hline 25 & 37 & $\mathrm{~F}$ & $2 \cdot 3$ & $3 \cdot 0$ & $(0.7$ \\
\hline 26 & 42 & $\mathrm{~F}$ & 0.8 & 1.5 & 0.1 \\
\hline 27 & 36 & M & $5 \cdot 4$ & $7 \cdot 1$ & $3 \cdot 8$ \\
\hline 28 & 44 & $\mathrm{~F}$ & (1). 2 & 0.1 & (0). 3 \\
\hline 29 & 39 & M & $5 \cdot 4$ & $1 \cdot 8$ & 9 \\
\hline 30 & 32 & $\mathrm{~F}$ & 0.8 & 1.5 & 0 \\
\hline 31 & 33 & $\mathrm{~F}$ & $1 \cdot 1$ & 1.6 & 0.6 \\
\hline 32 & 38 & M & $2 \cdot 5$ & $4 \cdot 5$ & 0.9 \\
\hline 33 & 39 & $\mathrm{~F}$ & $2 \cdot 6$ & 0.6 & 1.6 \\
\hline 34 & 32 & $\mathrm{~F}$ & 1.7 & 2.9 & 0.6 \\
\hline 35 & 41 & $\mathrm{M}$ & $1 \cdot 0$ & 1.5 & 0.6 \\
\hline 36 & 38 & $\mathbf{F}$ & 0.9 & $1 \cdot 8$ & 0 \\
\hline 37 & 40) & $\mathrm{F}$ & 0.5 & $1 \cdot 1$ & 0 \\
\hline 38 & 33 & $\mathrm{~F}$ & 0.5 & 0.7 & 0.2 \\
\hline 39 & 36 & $\mathrm{~F}$ & 0.5 & $1 \cdot 1$ & 0 \\
\hline 40 & 42 & $\mathrm{~F}$ & $(0.3$ & 0.6 & () \\
\hline 41 & 33 & $F$ & 0.3 & 0.3 & 0.2 \\
\hline 42 & 30 & $\mathrm{~F}$ & 0.1 & 0.2 & 0 \\
\hline 43 & 42 & $\mathrm{~F}$ & $(0.1$ & (). 1 & 0 \\
\hline 44 & 34 & $\mathrm{~F}$ & $(0.1$ & 0 & 0.1 \\
\hline 45 & 46 & M & 0.1 & $0 \cdot 1$ & 0 \\
\hline 46 & 46 & $\mathrm{M}$ & 0 & 0 & 0 \\
\hline 47 & 32 & $M$ & $2 \cdot 5$ & 1.9 & $3 \cdot 0$ \\
\hline 48 & 33 & $\mathrm{M}$ & 1.7 & $3 \cdot 2$ & 0.2 \\
\hline 49 & 41 & $\mathrm{~F}$ & 0.8 & 0.4 & $1 \cdot 1$ \\
\hline 50 & 57 & $\mathrm{M}$ & 0.9 & $1 \cdot 8$ & 0 \\
\hline
\end{tabular}

Tot. Amb. Rec $\%<4=$ percentage time with pH below 4 for the total monitoring and in the ambulant and recumbent periods.

limit for reflux than $\mathrm{pH} 3,4$, or 5 . We found no difference between these latter $\mathrm{pH}$ levels in contrast with Stanciu et al who, in a supine clinical study, found $\mathrm{pH} 5$ to be a better indicator of pathological gastro-oesophageal reflux than $\mathrm{pH} 4 .{ }^{1+}$ They used only symptoms as definition for disease, however, and did not carry out endoscopies on the normal subjects. Among our asymptomatic subjects, $9 \%$ had
Table 4 95th percentile of the reflux variables from 50 normal subjects

\begin{tabular}{|c|c|c|c|c|}
\hline & Tot & $A m b$ & Rec & Postp \\
\hline Percentage time $\mathrm{pH}<4$ & $3 \cdot 4$ & $4 \cdot 6$ & $3 \cdot 2$ & $7 \cdot 4$ \\
\hline Number of reflux episodes & 31 & 26 & 10 & 10 \\
\hline \multicolumn{5}{|l|}{ Number of episodes longer than } \\
\hline 5 minutes & 2 & 2 & 1 & 1 \\
\hline Length of longest episode ( $\mathrm{min}$ ) & 17 & 10) & 16 & 8 \\
\hline Mean number of $\mathrm{ep} / \mathrm{h}$ & $1 \cdot 4$ & $2 \cdot 6$ & $1 \cdot 1$ & $4 \cdot 3$ \\
\hline Clearance (min/episode) & $2 \cdot 6$ & $2 \cdot 7$ & $3 \cdot 6$ & $3 \cdot 8$ \\
\hline FDI & $2 \cdot 4$ & $6 \cdot 5$ & $1 \cdot 6$ & $16 \cdot 9$ \\
\hline
\end{tabular}

Tot = total monitoring time; $\mathrm{Amb}=$ ambulant period: $\mathrm{Rec}=$ recumbent period; Postp $=$ postprandial period.

a pathological endoscopy. Furthermore, the discriminant analysis used by Stanciu et al is only applicable on data that are normally distributed. The distributions of data from our $\mathrm{pH}$ monitorings have a pronounced skewness. The logistic regression used in the present study allows multivariate analysis on data that are not normally distributed. ${ }^{1:}$ Vitale $e t \mathrm{al}^{2+}$ have suggested the simultaneous use of all cut off limits from 3 to 6 . This combination is not found to be superior in our data. Consequently, we suggest a fall in $\mathrm{pH}$ to below 4 in the distal oesophagus to be used as definition of a reflux episode because of its simplicity, widespread use and as it efficaciously discriminates between subjects with and without gastrooesophageal reflux disease.

Using $\mathrm{pH} 4$ as the cut off limit, three single variables were equally good determinants of disease. In our study the combination of cumulative duration of reflux and frequency of reflux episodes in a single variable (FDI) is not superior to cumulative duration in contrast with the findings of Branicki et al. ${ }^{12}$ They did not, however, carry out endoscopies in the asymptomatic controls with resulting uncertainty in the separation of the groups. Furthermore, they have used the number of misclassified subjects as the criterion for selecting FDI as the best variable. In our opinion this is hazardous in these small patient materials with pronounced skewness of the data.

It is obvious from our study that many combinations of variables are equally potent as determinants of pathological gastro-oesophageal reflux, mainly because of a large covariation among the variables. For wider clinical use, it is essential to use a simple and easily comprehended presentation of the data obtained in $\mathrm{pH}$ monitorings. For this purpose it is preferable to avoid combinations of variables. The cumulative duration of reflux (percentage time with $\mathrm{pH}$ below 4) during the total monitoring fulfills these criteria and is simultaneously a good determinant of gastro-oesophageal reflux disease in our material.

The postprandial period is not as good a predictor of pathological gastroesophageal reflux as the 
ambulant and recumbent periods probably because of the physiological reflux that is known to occur after meals. ${ }^{26}$ Sontag et al have suggested that postprandial reflux is responsible for severe oesophageal mucosal disease. ${ }^{27}$ This finding is not contradicted by our study because we only have studied the ability of the different periods of the $\mathrm{pH}$ monitoring to differentiate illness from normality. In this respect, we also found the ambulant and recumbent periods to be equally good determinants although there is other evidence that recumbent reflux is the most noxious to the oesophagus. $262 x$

The analysis of gastro-oesophageal reflux by $\mathrm{pH}$ monitoring can distinguish pathological from physiological reflux. Furthermore, the $\mathrm{pH}$ monitoring should be able to quantify the amount and to identify the temporal profile of the pathological reflux in order to provide a rational basis for therapy. For the analysis of $\mathrm{pH}$ monitorings in the clinical routine use it is suitable to use percentage time below 4 during the total time together with percentage time below 4 ambulant and recumbent to identify the pattern of reflux.

Ciinical studies of gastro-oesophageal reflux inherit the difficulty of defining a proper patient group. If symptoms alone are used as criteria for disease patients with oesophageal motor disorders, coronary heart disease, peptic ulcer and gall bladder disease may be included in the patient group. This will give the test studied a falsely low sensitivity and may explain the differences in sensitivity and specificity of $\mathrm{pH}$ monitorings that are seen in the literature. ${ }^{617}$ Furthermore, the use only of symptoms as criteria for pathological gastro-oesophageal reflux may obscure the proper determinants of disease. In the present study we have used strict criteria for gastro-oesophageal reflux disease and not included reflux patients without oesophagitis. Consequently, the sensitivity found may not be true for mild forms of the disease. The aim has mainly been, however, to define the best determinants of disease obtained by 24 hour $\mathrm{pH}$ monitoring. Thus, further studies on larger patient numbers will be requested to investigate the characteristics in $\mathrm{pH}$ monitorings in different types of pathological gastro-oesophageal reflux. A difference in age was found between the patients and the normal subjects in the present study. Spence et al, however, ${ }^{29}$ found no difference in the results of $\mathrm{pH}$ monitoring between normal subjects of different age.

For the understanding of physiological reflux the investigation of asymptomatic controls is essential. The necessity of thorough investigations (including endoscopy) in these controls is emphasised by the presence of oesophagitis and hiatal hernia in some of our 'normal' volunteers.

We have shown that 24 hour oesophageal $\mathrm{pH}$ monitoring detects pathological gastro-oesophageal reflux with a high sensitivity and also has a high specificity. This is achieved with one single reflux variable; oesophageal $\mathrm{pH}$ of 4 or lower for more than $3.4 \%$ of the total time. The use of this criterion offers clear cut advantages as a method of analysis compared with that previously suggested. $\mathrm{pH}$ monitoring will play a major part in further research on gastrooesophageal reflux disease and is necessary for the evaluation of medical and surgical therapy. Furthermore, outpatient procedure seems most suitable for routine diagnosis.

We would like to thank Mrs Irja Långh for providing skilful technical assistance.

\section{References}

1 Tuttle SG, Betterello A. Grossman MI. Esophageal acid perfusion test and a gastroesophageal reflux test in patients with esophagitis. Gastroenterology 1960; 38: 861-72.

2 Skinner DB, Booth DJ. Assessment of distal esophageal function in patients with hiatal hernia and/or gastroesophageal reflux. Ann Surg 1970; 172: 627-37.

3 DeMeester TR, Ching-I Wang, Wernly JA, et al. Technique, indications and clinical use of 24 hour esophageal $\mathrm{pH}$-monitoring. J Thorac Cardiovasc Surg 1980; 79: 656-70).

4 Joelsson BJ, DeMeester TR, Skinner DB, LaFontaine E, Waters PF. O'Sullivan GC. The role of the esophageal body in the antireflux mechanism. Surgery 1982; 92: 417-24.

5 Stanciu C, Bennet JR. Oesophageal acid clearing: one factor in the production of reflux esophagitis. Gut 1974; 15: $852-7$.

6 Vitale GC, Cheadle WG, Sadek S, Michel ME, Cushieri A. Computerized 24-hour ambulatory esophageal pHmonitoring and esophagogastro-duodenoscopy in the reflux patient. Ann Surg 1984; 200: 724-8.

7 Branicki FJ, Evans DF, Ogilvie AL, Atkinson M, Hardcastle JD. Ambulatory monitoring of oesophageal $\mathrm{pH}$ in reflux oesophagitis using a portable radiotelemetry system. Gut 1982; 23: 992-8.

8 Choiniere L, Miller L, Ilves R, et al. Design and operation of portable datalogger. In: DeMeester TR. Skinner DB, eds. Esophageal disorders. New York: Raven Press, 1985: 519-23.

9 Martin CJ, Persano D, Kirsner RLG, et al. A simple system for ambulatory esophageal $\mathrm{pH}$-monitoring. In: DeMeester TR, Skinner DB, eds. Esophageal disorders. New York: Raven Press, 1985: 557-9.

10 DeMeester TR, Lafontaine E, Joelsson BE, et al. Relationship of a hiatal hernia to the function of the body of the esophagus and the gastroesophageal junction. J Thorac Cardiovasc Surg 1981; 82: 547-58.

11 Ask P, Edwall G, Johansson K-E, Tibbling L. On the use of monocrystalline antimony $\mathrm{pH}$ electrodes in gastro-esophageal functional disorders. Med Biol Eng Comput 1982; 20: 383-9. 
12 Branicki FJ, Evans DF, Jones JA, Ogilvie AL, Atkinson $M$, Hardcastle JD. A frequency-duration index (FDI) for the evaluation of ambulatory recordings of gastroesophageal reflux. BrJ Surg 1984; 71: 425-30.

13 Cox DR. Analysis of binary data. London: Chapman and Hall, 1970.

14 Stanciu C, Hoare RC, Bennet JR. Correlation between manometric and $\mathrm{pH}$ tests for gastro-esophageal reflux. Gut 1977; 18: 536-40.

15 DeMeester TR, Johnson LF. The evaluation of objective measurements of gastro-esophageal reflux and their contribution to patient management. Surg Clin N Am 1976; 56: 39-53.

16 DeMeester TR, Ching-I Wang, Johnson LF, Skinner DB. Comparison of clinical test for detection of gastroesophageal reflux. Eur Surg Res 1979; 11: suppl 2:13.

17 Fink SM, McCallum RW. The role of prolonged esophageal $\mathrm{pH}$-monitoring in the diagnosis of gastroesophageal reflux. JAMA 1984; 252: 116()-4.

18 Johansson K-E, Ask P, Tibbling L. Equipment design for 24-hr esophageal pH-monitoring. In: DeMeester TR, Skinner DB, eds. Esophageal disorders. New York: Raven Press, 1985: 505-8.

19 Lichter I. Measurement of gastro-esophageal acid reflux: its significance in hiatus hernia. Br J Surg 1974; 61: $253-8$.

20 Goldberg HI, Dodds WJ, Gee S, Montgomery C, Zboralske FF. Role of acid and pepsin in acute experimental esophagitis. Gastroenterology 1969; 56: 223-30.
21 Johnson LF, DeMeester TR. Twenty-four hour pHmonitoring of the distal esophagus. Am J Gastroenterol 1974; 62: 325-32.

22 Tuttle SG, Rufin F, Battanello A. The physiology of heartburn. Ann Intern Med 1961; 55: 292-300.

23 Hollander $\mathrm{F}$. What is $\mathrm{pH}$ ? Explanation of various measures of acidity employed in gastro-esophageal reflux. Gastroenterology 1945; 4: 497-508.

24 Vitale GC, Sadek F, Tulley FM, et al. Computerized 24hour esophageal $\mathrm{pH}$ monitoring: a new ambulatory technique using radiotelemetry. J Lab Clin Med 1985; 105: 686-93.

25 Kaye MD. Postprandial gastro-oesophageal reflux in healthy people. Gut 1977; 18: 709-12.

26 DeMeester TR, Johnson LF, Joseph GJ, Toscano MS, Hall AW, Skinner DB. Patterns of gastroesophageal reflux in health and disease. Ann Surg 1976; 184: 459-70.

27 Sontag S, Scnell T, O'Connel S, Serlovsky R, Dorociak P, Nemchausky B. Ambulatory 24 hour esophageal pHmonitoring in symptomatic gastroesophageal reflux and Barrets esophagus. Gastroenterology 1985; 88: 1594.

28 Atkinson M, Van Gelder A. Esophageal intraluminal $\mathrm{pH}$ recording in the assessment of gastro-esophageal reflux and its consequenses. Am J Dig Dis 1977; 22: 365-70.

29 Spence RAJ, Collins BJ, Parks TG, Love AHG. Does age influence normal gastro-oesophageal reflux? Gut 1985; 26: 799-801. 